\title{
Lymphoma without Peripheral Lymphadenopathy: An Approach to Definitive Diagnosis by Flowcytometry
}

\author{
Amar R*, Raja P and Meenakshi W \\ Department of Oncology, AIIMS, India
}

*Corresponding author: Amar Ranjan, Assistant Professor, Department of Oncology, All India Institute of Medical Sciences, New Delhi, India, Tel: 9968328620; E-mail: dr.amarranjan@rediffmail.com

\section{Case Report \\ Volume 1 Issue 2}

Received Date: July 14, 2017

Published Date: October 02, 2017

DOI: $10.23880 /$ hij-16000104

\section{Abstract}

Splenic lymphoma with circulating villous lymphocytes (SLVL) is an indolent B-cell neoplasm. Because of its rarity, a definitive diagnosis often becomes difficult. In this study we are going to discuss about two cases of SLVL. Despite being a variant of lymphoma peripheral lymphadenopathy is not found in such cases. Careful analysis of blood or bone marrow sample by flow cytometry may be helpful in getting the correct diagnosis.

Keywords: Marginal zone lymphoma; Flow cytometry; Lymphadenopathy; Immunohistochemistry

Abbreviations: SLVL: Splenic Lymphoma Villous Lymphocytes; MZL: Marginal Zone Lymphoma; MALT: Mucosa-Associated Lymphoid Tissue; PB: Peripheral Blood; BM: Bone Marrow; FCM: Flow cytometry; NHL: Non Hodgkin Lymphoma; LDH: Lactate Dehydrogenase; CR: Clinical Remission; SMZL: Splenic Marginal Zone Lymphomal; CLL: Chronic Lymphocytic Leukemia; MNDA: Myeloid Cell Nuclear Differentiation Antigen; FL: Follicular Lymphoma; HCL: Hairy Cell Leukemia; MCL: Mantle Cell Lymphoma; HCV: Hepatitis C Virus

\section{Introduction}

Marginal zone lymphoma (MZL) is a group of indolent B-cell Non Hodgkin Lymphoma. It forms $12 \%$ of all B-cell lymphomas. Median age at presentation is 65 year. It is of three subtypes. First, Extranodal MZL or mucosa-associated lymphoid tissue (MALT) lymphoma, the most common form, which represents $9 \%$ of all Bcell lymphoma. It involves stomach, small intestine, salivary gland, thyroid, eyes and lungs. There is a definite history of inflammation or autoimmune disorders e.g. H. pylori associated chronic gastritis. Second, Nodal MZL, involves lymph nodes and represents $2 \%$ of all B-cell lymphomas. Lastly Splenic MZL, affects spleen and blood. It represents $1 \%$ of all Bcell lymphoma [1].

\section{Case Report}

\section{Case 1}

A 45 year old male presented with history of fever, weight loss, fullness of abdomen and easy fatigability for 18 months. Clinical examination showed massive tender splenomegaly, enlarged tonsil, umbilical hernia, non palpable liver \& raised Serum Alkaline Phosphatase 489 U/L (80-240). Contrast Enhanced Computed Tomography showed massive splenomegaly with infarcts, Portal hypertension, moderate ascites and umbilical hernia.

Peripheral Blood (PB) smear \& Bone Marrow (BM) Aspirate showed abnormal lymphoid cells 50\% (Figure 1-Figure 4) \& 30\% respectively. Some lymphocytes showed polar villus projections. BM biopsy showed infiltration by atypical lymphoid cells, positive for $\mathrm{CD}$ 20, CD 23, bcl-2 \& negative for CD3, CD 10, CD 5 , cyclinD1 on IHC. Flow cytometry (FCM) showed 10\% CD19+ve abnormal lambda light chain restricted lymphoid cells, which were positive for CD45, CD20 (bright), CD 11C, CD 25 (dim) \& negative For CD123, CD 103, CD 5 \& CD 38. 

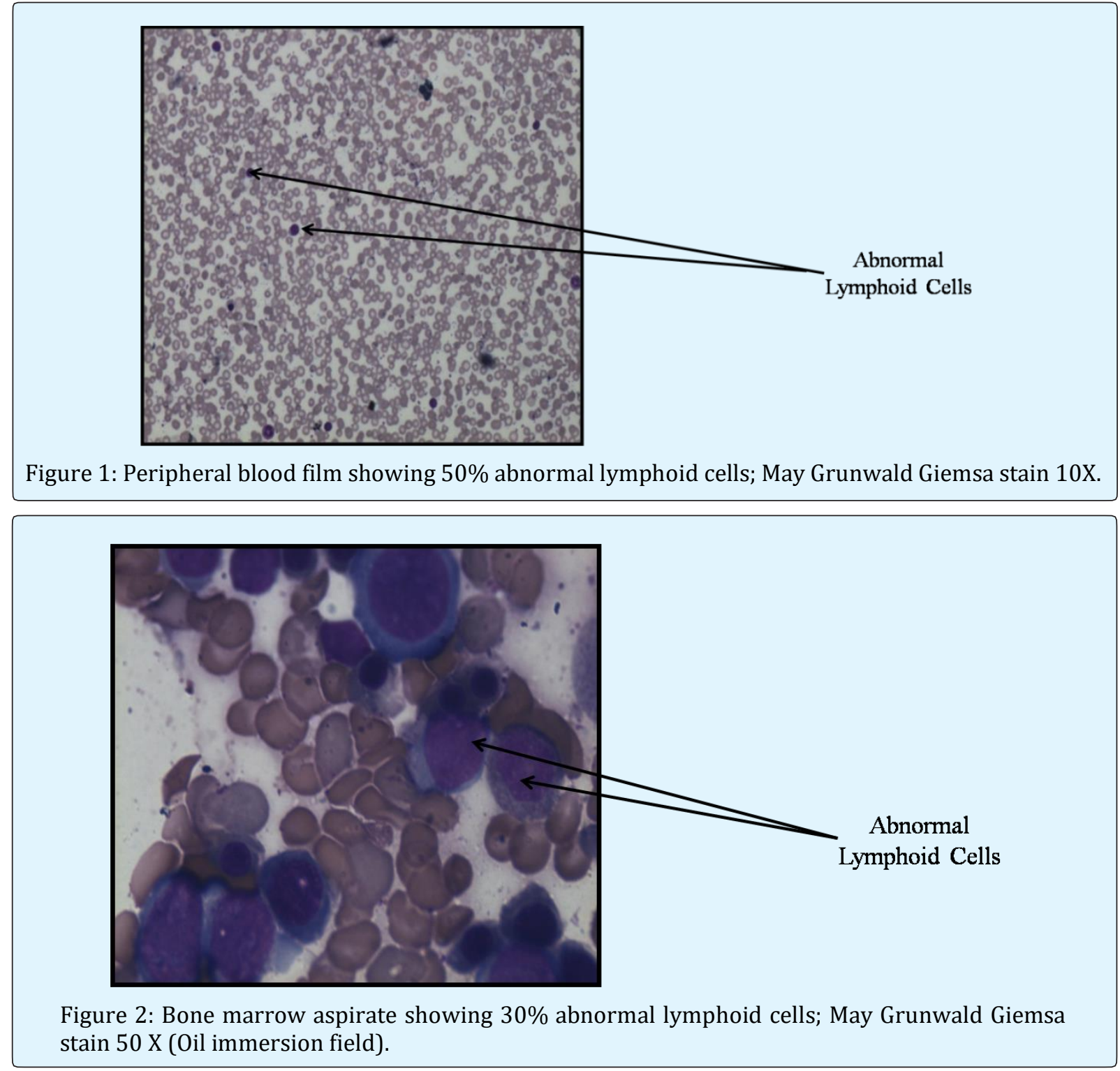

Figure 2: Bone marrow aspirate showing 30\% abnormal lymphoid cells; May Grunwald Giemsa stain 50 X (Oil immersion field).

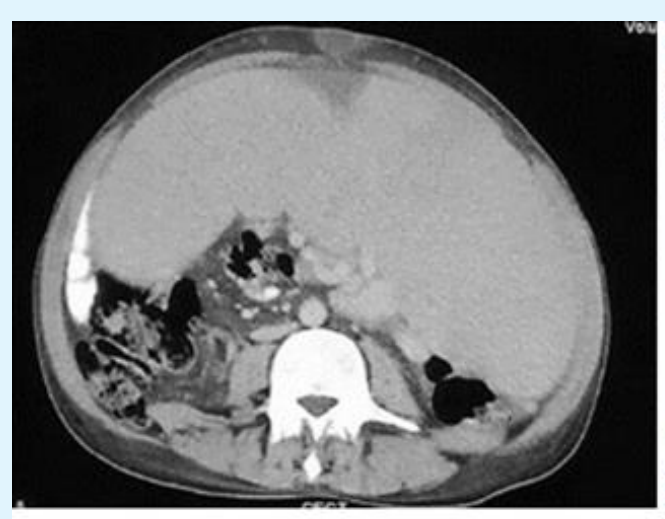

(a)

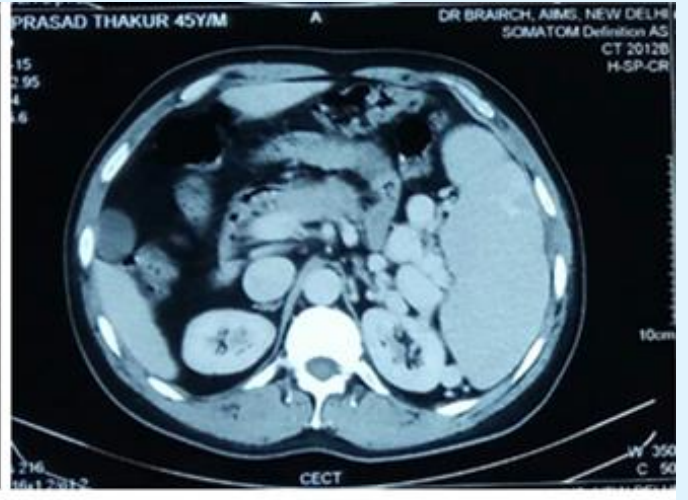

(b)

Figure 3 (a): Pretreatment axial CT image showing massive splenomegaly with peripheral infarct Figure 3 (b): Post treatment axial CT image demonstrating marked regression of splenomegaly. 
Figures of case 1: Labelled diagram of report of by Flow cytometry.
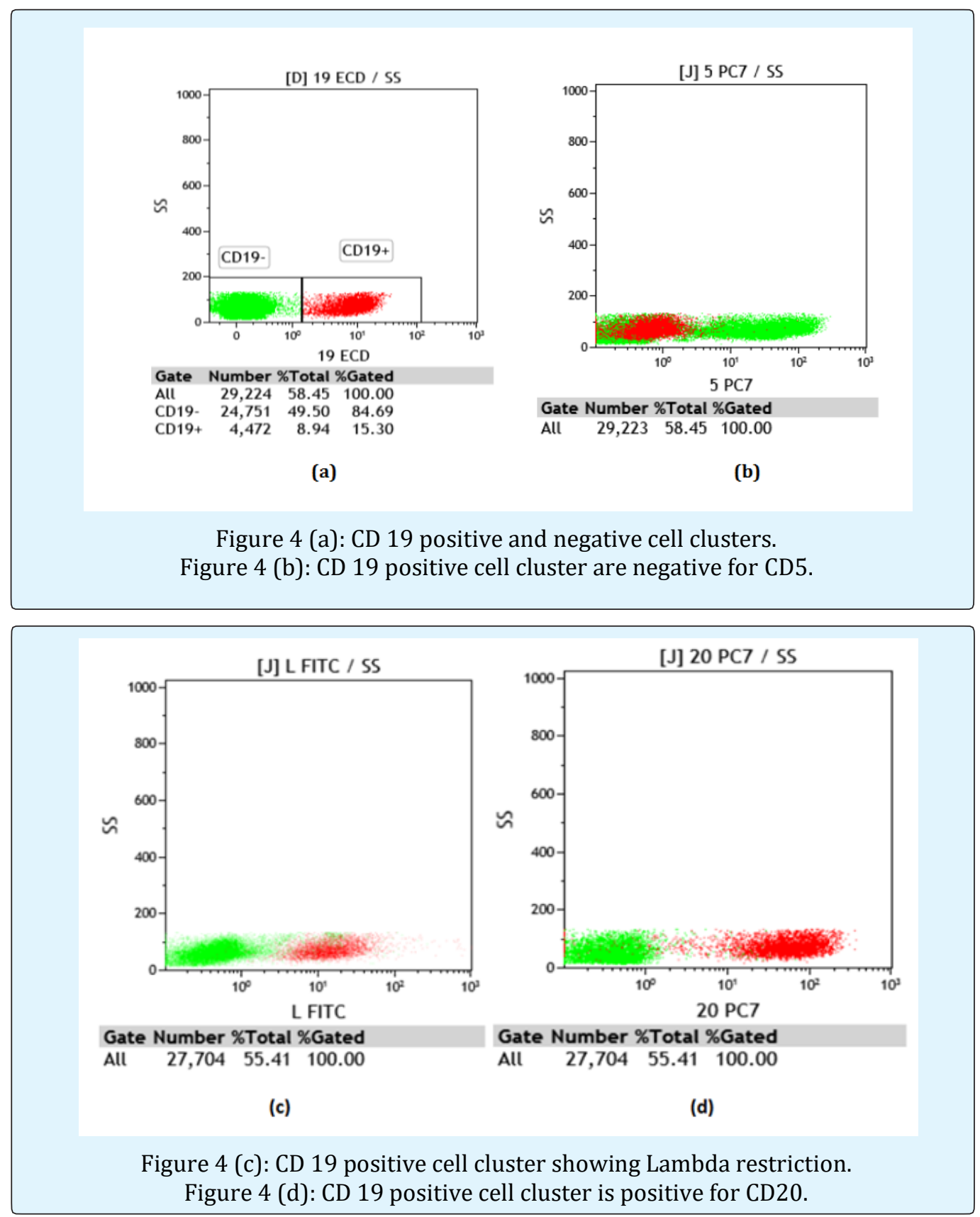

A diagnosis of B-cell low grade Non Hodgkin Lymphoma (NHL) with predominant splenic involvement i.e. SLVL was considered. After six cycles of Rituximab \& Bendamustine, significant partial response with complete resolution of ascites \& marked regression in splenomegaly was noted. Presently the patient is showing treatment free survival for last thirty five months, is on follow up every six months.

\section{Case 2}

A 62 year female presented with fever, weight loss and B-symptoms for 4-6 months. There was massive splenomegaly with mild hepatomegaly \& no lymphadenopathy. Patient was hypertensive. Peripheral blood film showed pancytopenia. BM aspirate showed $30 \%$ abnormal lymphoid cells. Biopsy showed abnormal lymphoid cells positive for CD 20, CD23 and negative for CD3, CD5, Cyclin D1 and DBA44. FCM showed 20\% abnormal lymphoid cell positive for CD 20, CD 22, CD 10, CD 38, FMC-7 \& negative for CD 3, CD 23, CD 11C, CD 103. NHL stage IV was considered, as bilateral axillary lymphadenopathy developed four months after first presentation. On follow up after one year, repeat BM biopsy showed abnormal lymphoid cell infiltration 


\section{Haematology International Journal}

positive for CD3 (previously -ve) \& CD 20 \& negative for CD10 (previously +ve) \& BCL-2. Eight cycles of CVP (cyclophosphamide, Vincristine \& Prednisolone) was given. Spleen became non palpable and the patient got clinical remission (CR). After one year of $\mathrm{CR}$, patient presented with $\mathrm{HBsAg}++$ and markedly raised value of serum lactate dehydrogenase (LDH). BM aspirate / biopsy showed no NHL infiltration. Now patient is on therapy for Hepatitis B. Later the patient developed chronic liver disease with portal hypertension, for which follow up is going on (Figure 5-9).

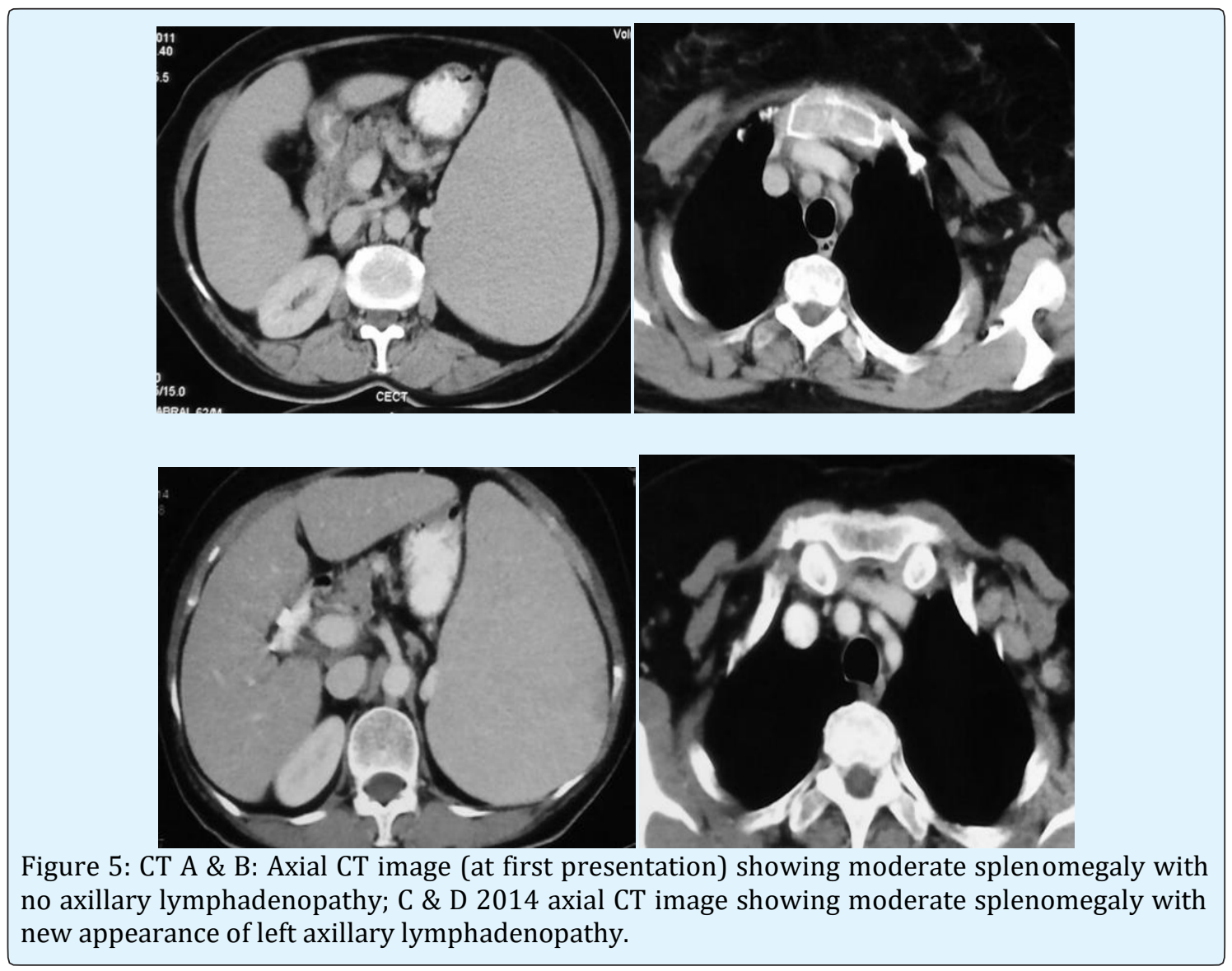

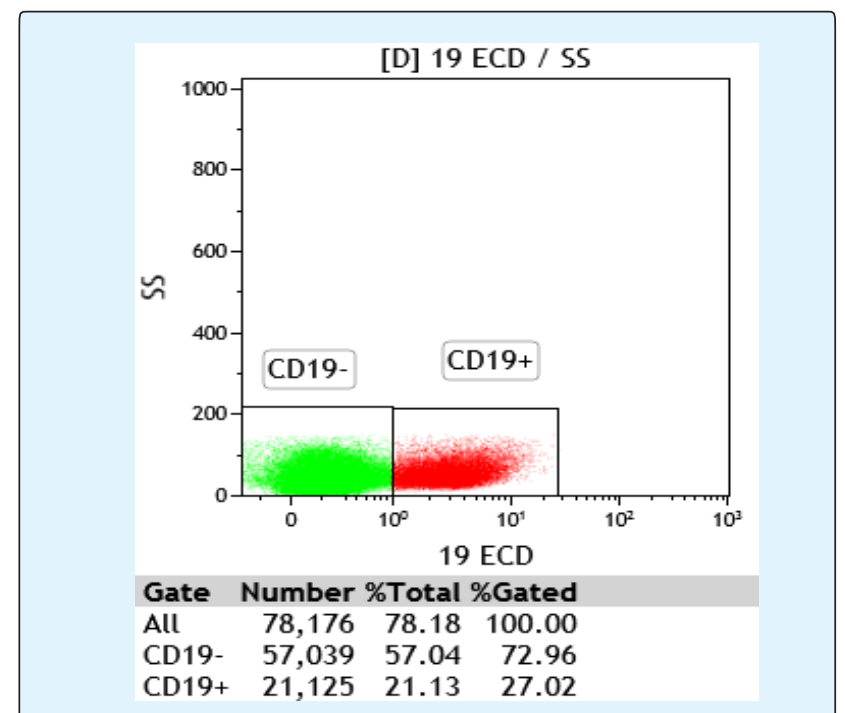

Figure 6 (a): CD 19 positive and negative cell clusters.

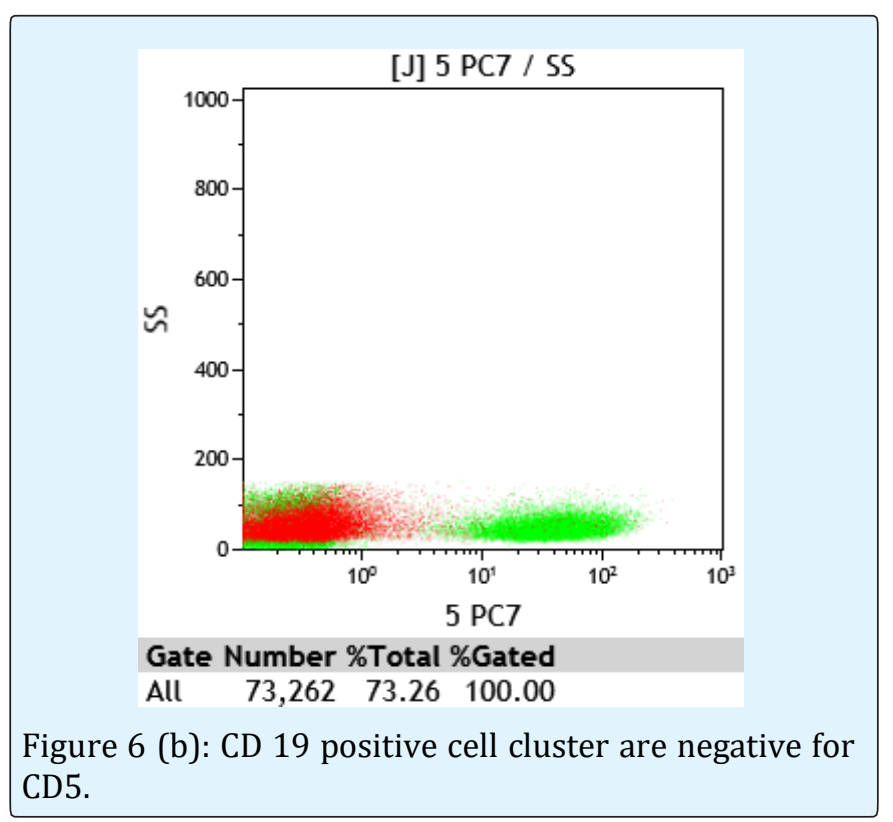



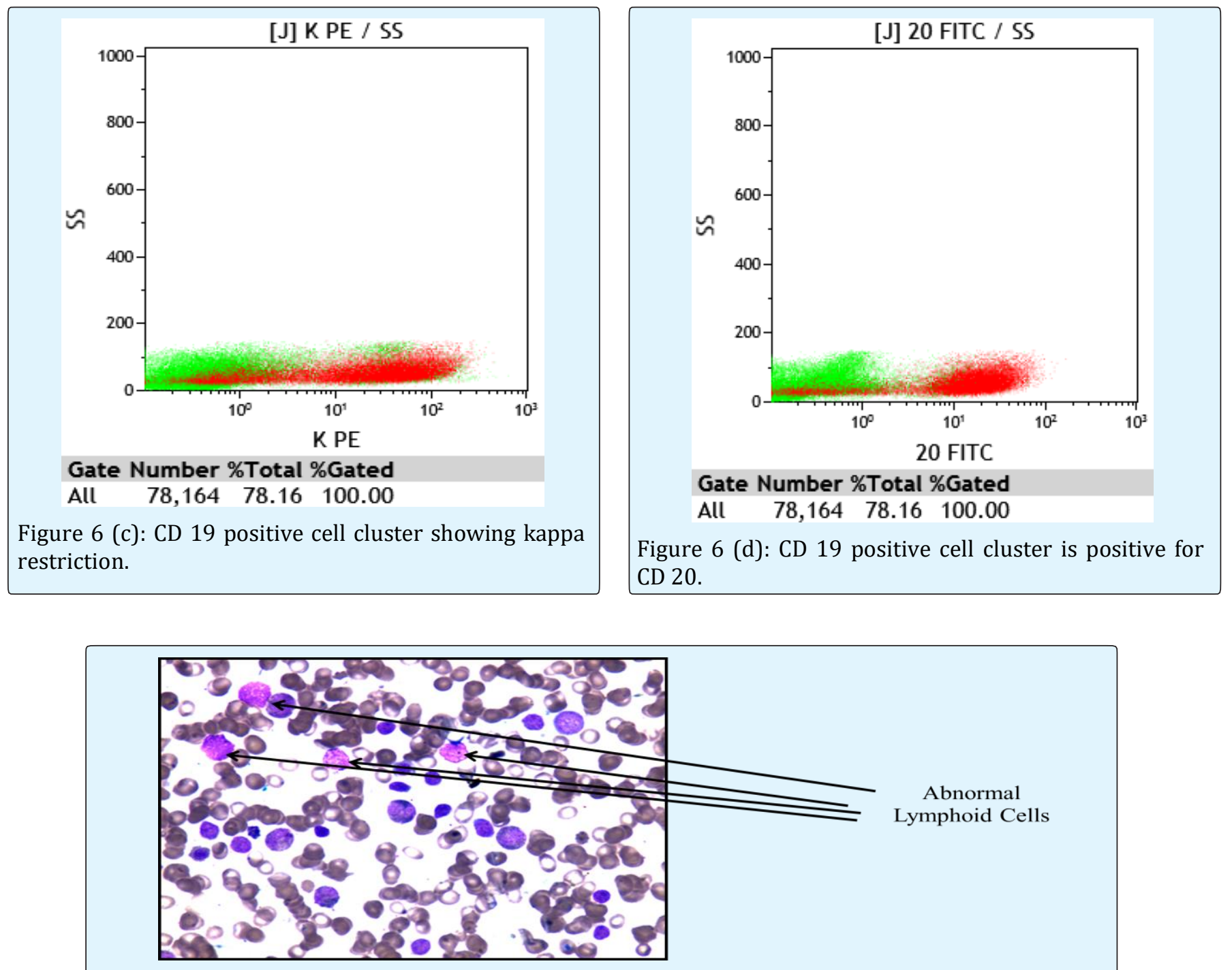

Figure 7: BMA smear showing abnormal lymphoid cells, May Grunwald Giemsa (MGG) stain, 50 X.

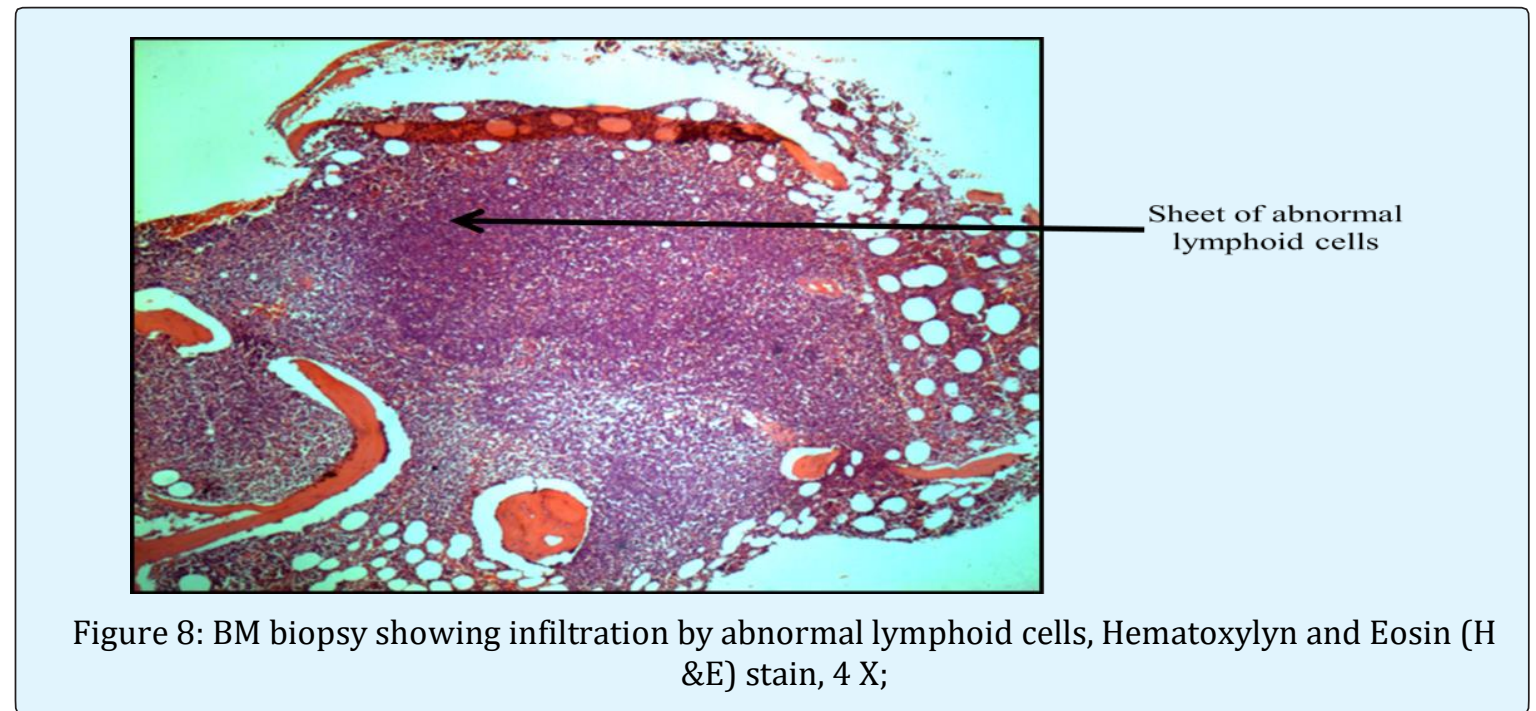




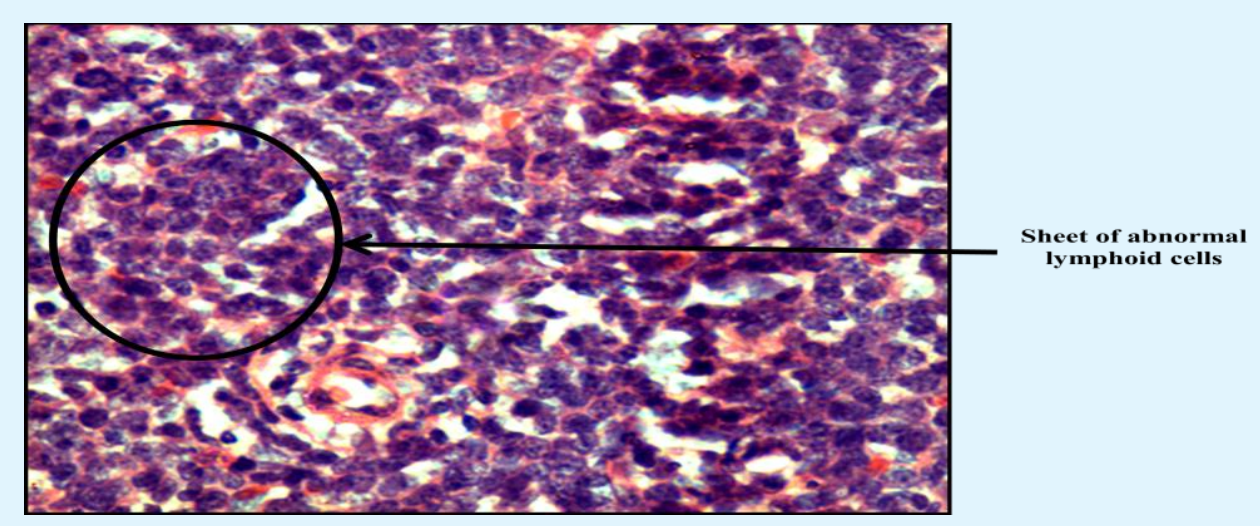

Figure 9: BM biopsy showing sheets of abnormal lymphoid cells, H \&E stain, $50 \mathrm{X}$, oil immersion field.

\section{Discussion}

Presently diagnostic hematopathology depends on immunophenotyping using flow cytometry and immunohistochemistry in combination with the cytomorphology and histology. Selected cases may need additional ancillary cytogenetic and molecular techniques for diagnosis. Flow cytometry offers the sensitive detection of antigens for which antibodies may not be available for IHC e.g. CD13, CD14, CD19, CD33 etc. But some antibodies may be better evaluated in paraffin tissue eg, CD15 for Reed-Sternberg cells, Bcl-6, Bcl-2, ALK-1, cyclin D1 and cytoplasmic $\kappa$ and $\lambda$. However IHC offers preservation of architecture. It should be used as a complimentary tool. FCM data should always be correlated with light microscopy [2]. In our cases both the procedures FCM as well as IHC along with routine light microscopy were performed. Results were correlated well in both the procedures. IHC was performed especially for the markers for which antibody to be used in FCM was not available like Cyclin D1, DBA44 etc. FCM involved larger panel. Splenic marginal zone lymphoma (SMZL) lacks any specific diagnostic marker or unique histopathological finding. It has a variable clinical outcome. Aggressive course has been seen in $30 \%$ of cases. Its diagnosis has remained a challenge for hematologists [3].

Metcalf RA, et al. [4] studied expression of Myeloid cell nuclear differentiation antigen (MNDA) by immunohistochemistry in cases of lymphoma. They included 440 tissue sections and 216 bone marrow biopsy sections showing neoplastic lymphoid infiltration. MNDA expression in MZL in nodal, extranodal and splenic variant was $67 \%, 61 \%$ and $24 \%$ respectively [4].

$\mathrm{Hu} \mathrm{Y}$, et al. [5] studied 6 cases of SMZL patients, which expressed CD19 + and CD20 +, but CD10 expression was negative, 4 patients expressed CD5-, 2 patients expressed CD5+. The expressions of CD23, CD38, ZAP-70, CD11c, CD103, CD123, Cyclin D1 were negative. These findings approximate with our finding. Thus, the diagnosis is made by exclusion of Chronic lymphocytic leukemia (CLL), Follicular lymphoma (FL), Hairy cell leukemia (HCL) \& Mantle cell lymphoma (MCL) combined with histopathological pattern on BM \&/or splenic biopsy [5].

Almost all cases of SMZL show bone marrow involvement. Occasional negative cases may be seen. However this may be easily recognized without immunohistochemistry [6]. Peripheral blood involvement may be seen in different percentages. In cases of pancytopenia it may remain undetectable.

With peripheral blood involvement, abnormal mature B lymphocytes with irregular cytoplasmic borders and villous projections can be identified. Aggressive variants may have larger cells with prominent nucleoli [7]. In cases with favorable prognostic factors like mild lymphocytosis and no cytopenia, patients are kept on "wait and watch" policy [8]. 5-year overall survival rate in untreated cases is approximately 88\% [9]. Costa RS, et al. [10] reported a case of SMZL with plasmacytic differentiation and bone marrow infiltration, which closely mimicked multiple myeloma. This case was also associated with membranous glomerulonephritis (renal failure, one of the diagnostic criteria of multiple myeloma) [10].

Different epidemiological studies have shown the association of hepatitis $\mathrm{C}$ virus (HCV) infection with Bcell non-Hodgkin's lymphoma. It is most common in endemic geographical zone such as Italy, Japan and southern parts of United States.

Marginal zone lymphoma is the most common type of lymphoma that is associated with HCV infection. 
Recent studies show that antiviral therapy is effective in treating indolent lymphoma which has shown HCV positivity. This is the strong supportive evidence of association of HCV and lymphoma [11].

The mechanism of development of B cell lymphoma is yet to be determined. Quinin ER 2001 proposed continuous antigenic stimulation of marginal zone B cell in spleen by HCV antigen, especially E2 viral antigen may be the possible mechanism of development of SLVL [12]. But HCV may have oncogenic effect on B cell directly [13].

Majority of patients with splenic MZL show an indolent course. The median overall survival is 10 years. Therapy is oriented towards symptoms and splenomegaly. Asymptomatic patients are kept under observation.

Splenectomy was the treatment of choice before Rituximab era. Use of Rituximab has made splenectomy unnecessary as an upfront therapy [14]. Studies show Rituximab as a better choice over splenectomy [15]. If chemotherapy stronger than Rituximab monotherapy is needed, purine analogues such as Fludarabine are a better choice. Many combination therapies are on trial [16]. The both of our cases were symptomatic \& managed by different therapeutic panels.

\section{Conclusion}

Symptoms in SMZL peculiar to other lymphoma are PB involvement \& no peripheral LAP at presentation. It should be correctly named as leukemia rather than lymphoma. In case of pancytopenia, BMA gives the clue. However, Flow cytometry has become the essential tool to achieve correct diagnosis. Unfortunately in our country very few centers are there where FCM is available due to cost factor. Further studies are also needed to look at its association with $\mathrm{HCV}$ in our country.

\section{Acknowledgement}

The authors have no conflict of interest to declare. This report was not supported by any funding agency.

\section{References}

1. Saadoun D1, Suarez F, Lefrere F, Valensi F, Mariette $\mathrm{X}$, et al. (2005) Splenic lymphoma with villous lymphocytes, associated with type II cryoglobulinemia and HCV infection: a new entity. Blood 105(1): 74-76.
2. Dunphy CH (2004) Applications of flow cytometry and immunohistochemistry to diagnostic hematopathology. Arch Pathol Lab Med 128(9): 1004-1022.

3. Watkins AJ, Huang Y, Ye H, Chanudet E, Johnson N, et al. (2010) Splenic marginal zone lymphoma: characterization of $7 q$ deletion and its value in diagnosis. J Pathol 220(4): 461-474.

4. Metcalf RA, Monabati A, Vyas M, Roncador G, Gualco $G$, et al. (2014) Myeloid cell nuclear differentiation antigen is expressed in a subset of marginal zone lymphomas and is useful in the differential diagnosis with follicular lymphoma. Human Pathol 45(8): 1730-1736.

5. Hu Y, Chen Y, Wang LH, Chen X, Fang F, et al. (2014) Identification of splenic marginal zone lymphoma from B lymphoproliferative disorders by flow cytometry. J Experimental Hematol 22(2): 349-356.

6. Franco V, Florena AM, Campesi G (1996) Intrasinusoidal bone marrow infiltration: a possible hallmark of splenic lymphoma. Histopathology 29(6): 571-575.

7. Lloret E, Mollejo M, Mateo MS, Villuendas R, Algara $\mathrm{P}$, et al. (1999) Splenic marginal zone lymphoma with increased number of blasts: an aggressive variant? Hum Pathol 30(10): 1153-1160.

8. Catovsky D, Matutes E (1999) Splenic lymphoma with circulating villous lymphocytes/splenic marginal-zone lymphoma. Semin Hematol 36(2): 148-154.

9. Troussard X, Valensi F, Duchayne E, Garand R, Felman P, et al. (1996) Splenic lymphoma with villous lymphocytes: clinical presentation, biology and prognostic factors in a series of 100 patients. $\mathrm{Br}$ J Haematol 93(3): 731-736.

10. Costa RS, Chahud F, Neto OM, Moyses-Neto M, Romão EA, et al. (2013) Membranous glomerulonephritis associated with splenic marginal zone lymphoma mimicking multiple myeloma. Clin Nephrol 79(6): 488-493.

11. Arcaini L, Bruno R (2010) Hepatitis C virus infection and antiviral treatment in marginal zone lymphomas Curr Clin Pharmacol 5(2): 74-81.

12. Quinin ER, Chan $\mathrm{CH}$, Hadlock KG, Foung SK, Flint $\mathrm{M}$, et al. (2001) The B-cell receptor of a hepatitis $C$ virus (HCV)-associated non-Hodgkin lymphoma binds the viral E2 envelope protein, implicating 


\section{Haematology International Journal}

HCV in lymphomagenesis. Blood 98(13): 37453749.

13. Agnello V, Abel G, Elfahal M, Knight GB, Zhang QX (1999) Hepatitis C virus and other flaviviridae viruses enter cells via low density lipoprotein receptor. Proc Natl Acad Sci USA 96(22): 1276612771.

14. Parry-Jones N, Matutes E, Gruszka-Westwood AM, Swansbury GJ, Wotherspoon AC (2003) Prognostic features of splenic lymphoma with villous lymphocytes: a report on 129 patients. Br J Hematol 120(5): 759-764.
15. Kalpadakis $\mathrm{CH}$, Pangalis G, Vassilakopoulos TP, Sachanas SP, Kontopidou F, et al. (2011) Treatment of Splenic Marginal Zone Lymphoma with Rituximab Monotherapy in 59 Patients. Blood 118(21): 2712.

16. Brown JR, Friedberg JW, Feng Y, Scofield S, Phillips $\mathrm{K}$, et al. (2009) A phase 2 study of concurrent fludarabine and rituximab for the treatment of marginal zone lymphomas. Br J Hematol 145(6): 741-748. 